\title{
Adelbert Denaux, Peter De Mey (eds.), The Ecumenical Legacy of Johannes Cardinal Willebrands (1909-2006)
}

Leuven, Peeters, coll. « Bibliotheca Ephemeridum Theologicarum Lovaniensium », CCLIII, 2012, XIII-376 p.

\section{Willem Frijhoff}

\section{OpenEdition}

\section{Journals}

Édition électronique

URL : https://journals.openedition.org/assr/28224

DOI : $10.4000 /$ assr.28224

ISSN : $1777-5825$

\section{Éditeur}

Éditions de l'EHESS

Édition imprimée

Date de publication : 31 décembre 2016

Pagination : 300

ISSN : 0335-5985

Référence électronique

Willem Frijhoff, « Adelbert Denaux, Peter De Mey (eds.), The Ecumenical Legacy of Johannes Cardinal Willebrands (1909-2006) », Archives de sciences sociales des religions [En ligne], 176 | octobredécembre 2016, mis en ligne le 17 juillet 2017, consulté le 21 septembre 2021. URL : http:// journals.openedition.org/assr/28224 ; DOI : https://doi.org/10.4000/assr.28224

Ce document a été généré automatiquement le 21 septembre 2021.

(c) Archives de sciences sociales des religions 


\section{Adelbert Denaux, Peter De Mey (eds.), The Ecumenical Legacy of Johannes Cardinal Willebrands (1909-2006)}

Leuven, Peeters, coll. « Bibliotheca Ephemeridum Theologicarum Lovaniensium », CCLIII, 2012, XIII-376 p.

Willem Frijhoff

\section{RÉFÉRENCE}

Adelbert Denaux, Peter De Mey (eds.), The Ecumenical Legacy of Johannes Cardinal Willebrands (1909-2006), Leuven, Peeters, coll. «Bibliotheca Ephemeridum Theologicarum Lovaniensium », CCLIII, 2012, XIII-376 p.

1 Composé d'une sélection des contributions de deux colloques, ce volume apparaît un peu hétéroclite : associant des évocations personnelles et des témoignages ponctuels (ainsi par Thomas Stransky à Jérusalem ou Paul Werner Scheele à Würzburg) à des articles plus larges d'une érudition solide, il se veut un hommage à un des pionniers du mouvement œcuménique dans sa première phase, en même temps qu'un instrument de travail. Anton Houtepen passe en revue les années de formation du jeune Willebrands, d'abord séduit par les rédemptoristes, puis ordonné prêtre séculier du diocèse de Haarlem. Après ses études à l'Angelicum de Rome, il travaille quelques années dans une paroisse d'Amsterdam avant d'être nommé professeur de philosophie, puis président $\mathrm{du}$ grand-séminaire de son diocèse à Warmond. Ses multiples activités dans le mouvement œcuménique international et ses contacts avec le cardinal Bea lui valent en 1960 la nomination comme secrétaire du Secrétariat pour l'Unité Chrétienne. Nommé évêque titulaire en 1964 et créé cardinal en 1969, il succède alors au cardinal Bea comme président de ce Secrétariat. Mais en 1975, il est nommé archevêque d'Utrecht 
comme successeur du cardinal Alfrink, tout en conservant ses fonctions romaines. Il se démet de son archevêché en 1983, mais continue jusqu'en 1989 d'assurer son travail au Secrétariat romain pour l'Unité. Intellectuel actif et théologien fécond jusqu'à l'âge de 90 ans, la bibliographie complète de ses écrits, réunie ici par Maria Ter Steeg, comprend pas moins de 483 numéros.

2 Parmi les articles de fond, on lira en particulier celui de Terrence Merrigan sur la fascination de Willebrands pour la pensée de John Henry Newman et son idée d'un Oratoire - elle-même tributaire de Bérulle, absent de ce volume qui reste près du $\mathrm{xx}^{\mathrm{e}}$ siècle -, déjà le sujet de sa thèse de philosophie soutenue à Rome en 1937, et dont Willebrands rêvait toujours de réaliser l'équivalent aux Pays-Bas. Peter De Mey analyse dans le détail son rôle décisif comme secrétaire de la Conférence catholique pour les Questions œcuméniques (1952-1963). Mauro Velati en fait de même pour le Concile Vatican II et l'élaboration du décret Unitatis Redintegratio sur l'œcuménisme, et Nostra Aetate sur le judaïsme (1965). Theo Salemink analyse prestement les carnets du cardinal récemment retrouvés et publiés depuis lors, couvrant quelques-unes de ses années les plus sensibles. Parmi les exposés sur sa pensée théologique en matière œcuménique et son ecclésiologie, marquée par la conviction que catholicité égale pluralisme - «a variety of typoi " manifestera le caractère pleinement catholique et apostolique de l'Église, disait-il (p.137) - je signale en particulier l'article de Jared Wicks qui éclaire notamment le sens que Willebrands a donné à l'affirmation très controversée de l'encyclique Lumen gentium, selon laquelle l'Église du Christ "subsistit in " l'Église catholique. Ses contacts avec les Églises d'Orient, très importants à ses propres yeux, sont détaillés avec empathie par Michel Van Parys. D'autres articles concernent le Conseil mondial des Églises et différentes Églises protestantes, suivis de quatre contributions sur le judaïsme, et plusieurs témoignages. Un index des noms très fourni clôt le volume.

3 Willebrands fut longtemps l'adjoint du cardinal Bea. Il était, et est resté pendant de longues décennies, un proche ami et confident de Frans Thijssen (1904-1990), prêtre du même diocèse et collaborateur du Secrétariat romain pour l'Unité, esprit plus ardu que Willebrands lui-même et qui, nommé ou cité dans quasiment tous les articles de ce recueil, aurait sans doute mérité un article à part. Avec Willebrands, qui était par excellence l'homme des contacts, Bea et Thijssen ont donné vie et forme au mouvement œcuménique dans l'Église catholique, mais toujours dans les cadres relativement étroits des structures ecclésiales, ce qui eut comme effet involontaire qu'en fin de compte, le clivage entre hiérarchie et communautés chrétiennes se creusant, le mouvement a échappé à leurs intentions. Sous plusieurs contributions à ce volume on sent le regret d'une époque dont le lien avec l'actualité se volatilise. L'œcuménisme ecclésial est devenu une stratégie officielle, mais a perdu de son ardeur et de son audace initiales. Les Églises sœurs prennent d'autres chemins, alors que les vraies collaborations se font maintenant massivement en marge des institutions qui ellesmêmes ont dû mal à justifier leur légitimité dans une société qui s'individualise jusqu'au plus profond de la vie religieuse. Il manque à ce volume, par conséquent, une interrogation substantielle et actualisée sur la question posée dans son titre même : l' héritage œcuménique. Willebrands était-il un précurseur du présent, ou appartient-il déjà à une histoire révolue? Que reste-t-il de son œuvre, à part des documents historiques parfois exhumés par surprise (car Willebrands a toujours eu le souci des archives), et le souvenir d'un homme probe et prudent, pétri de la conviction 
qu'œcuménisme égale consensus, et associant avec bonheur la réflexion théologique aux initiatives pastorales? Quelles traces de son travail trouve-t-on encore dans l'état actuel des communautés chrétiennes? Dans sa contribution de clôture, le cardinal Walter Kasper s'essaie bien à un bilan, mais il reste dans les paramètres ecclésiaux définis par le concile et les papes ultérieurs, sans vraiment approcher la question du point de vue des croyants.

Ce volume porte par moments de forts accents hagiographiques, même dans les articles savants. Les mots critiques sont prudents et souvent suivis d'un justificatif rapide. Si les débats et conflits, par exemple avec son compatriote Willem Visser't Hooft, président du Conseil mondial des Églises (tel le fameux «incident de Rhodes» en 1959), sont amplement évoqués, Willebrands y remplit presque toujours le beau rôle. Tout cela fait partie du genre commémoratif et n'aurait pas d'importance s'il ne manquait pas une analyse de ce qu'on peut probablement appeler le seul vrai échec du cardinal Willebrands : son épiscopat d'Utrecht, comme primat des Pays-Bas, dans les années cruciales 1975 (effectivement 1976)-1983. Échec d'autant plus cuisant que son successeur Adriaan Simonis, archevêque d'Utrecht de 1983 à 2007, en dépit de sa volonté d'harmoniser les rapports tendus dans son diocèse, était d'emblée perçu comme une créature imposée par le Vatican et dépourvue des hautes qualités intellectuelles et humaines que les Néerlandais attendaient alors de leurs évêques et qui avaient été parfaitement incarnées par Willebrands lui-même. Contrairement à ce dernier, Simonis polarisait les fidèles en croyant que la main ferme, le commandement et le culte du secret étaient des instruments aptes à réduire à l'obédience romaine cette bande d'insurgés. Mais cette époque était bien passée aux Pays-Bas, peut-être le pays le plus décatholicisé de l'Europe en ce moment, où les Églises se ferment par centaines (ou se reconvertissent en mosquées) et les paroisses disparaissent à tour de bras, et où les scandales autour des comportements des prêtres et religieux dans le passé se succèdent. L'Église catholique y a perdu tout impact réel dans la société, et son appartenance même est devenue pour beaucoup un aveu honteux ou qui fait sourire. Théologien à la hauteur de l'actualité et bon administrateur, prêt à l'écoute et conciliant, ayant de surcroît l'oreille des autorités ecclésiales et séculières, et déjà paré de son aura de cardinal, Willebrands aurait pu être un archevêque d'autant plus performant que son diocèse reflétait parfaitement cette société pluriconfessionnelle qui avait été son souci théologique primordial et l'objet de ses fonctions antérieures. Une épreuve œcuménique par les faits, en somme. Mais prudence, modération et consensus, les qualités premières du cardinal, étaient passés de mode aux Pays-Bas, et les maladresses du Vatican (tel le synode des évêques néerlandais commandés à Rome en 1980) ont, de l'aveu de Willebrands lui-même, augmenté la polarisation religieuse dans son pays.

5 Outre les auteurs au regard externe qui abondent dans ce volume, il aurait probablement fallu un témoignage de l'intérieur de son archidiocèse sur l'action du cardinal comme archevêque pour en rendre vraiment compte et faire de ce livre un vrai recueil biographique. Car en réalité le cardinal Willebrands était tout le contraire d'un personnage en carton, d'allure bureaucratique. Intellectuel et administrateur d'allure internationale, rompu aux efforts unitaires, il a sincèrement et activement essayé de réconcilier les contraires et de créer dans son archidiocèse et dans l'Église néerlandaise tout entière cette unité des opposants et des tendances variées qu'il a toujours promu dans l'Église mondiale. Mais il portait probablement trop la marque de l'appareil hiérarchique romain pour être pleinement crédible dans l'archidiocèse où on 
l'avait parachuté de l'extérieur, alors que la succession intradiocésaine y avait été la règle. Lorsque ses efforts avaient visiblement échoué et que l'occasion s'est présentée, il a eu l'honnêteté de se démettre de ses fonctions dans l'Église de son pays. Une analyse de cette période somme toute peu heureuse de sa trajectoire, voilée dans ce recueil, et de son rôle concret dans cette conjoncture aurait certainement aidé à affiner les présentations nombreuses de son caractère et de ses actions que l'on trouve dans ce volume - présentations et récits plutôt racontés et détaillés que vraiment analysés et qui portent bien souvent la marque d'un a priori favorable que l'historien est toujours bien inspiré d'approcher avec circonspection. 